\title{
Contraceptive choice and use of methods among young women in Namibia
}

\author{
By \\ Nelago Indongo \\ University of Namibia, Windhoek \\ Namibia
}

\begin{abstract}
The present study analyses the factors affecting contraceptive use and method choice among young women (15-24 years) in Namibia. It also explores ways to improve the accessibility of health facilities and family planning services for young Namibian women with reproductive health needs. The study draws on largely quantitative data provided by the 2000 Namibian Demographic and Health Survey (NDHS) but also includes vignettes from focus group discussions with young women. The logistic regression method has been applied to examine the determinants of contraceptive use and method choice. The study examines the level of knowledge of contraceptive methods and sources of supply, decisions leading to contraceptive use and choice as well as service delivery and the accessibility of contraception to potential users. The findings suggest that programmatic strategies should seek to improve parent-child communication, strengthen educational outlets of information, and lead to the implementation of effective policy to cater for a potentially growing number of young contraception-users in Namibia.

Key words: sexual and reproductive health, contraceptive use, contraceptive method choice, communication on family planning issues, Namibia

\section{Résumé}

La présente étude analyse les facteurs determinant l'usage des contraceptives et le choix des méthodes pour les jeunes femmes de l'âge de 15 à 24 ans en Namibie. L'étude examine les moyens pour améliorer l'accès aux services de soins de santé dans les centre de planification familiale en matière de reproduction.L'étude se base en partit des données tirées de l'enquête quantitative démographique et soins de santé realisée en 2000 en Namibie (NDHS-Namibian Demographic and Health Survey), de cette étude, s'ajoute aussi les données provenant des goupes de discussions avec les jeunes femmes namibiennes.L'étude examine le degrée de connaissances de l'usage du contraceptif, les fournisseurs de ces services de santé, decision qui pousse les jeunes femmes à chosir la method et soins offerts par les services de planification familiale. La méthode de regression logistique a été utilisée pour l'examination des résultats provenant de l'usage du contraceptifet le choix du méthode utilisée. Les résultats de l'étude révèlent que les stratégies programmatiques devraient chercher à améliorer la communication entre parent-enfant, renforcer l'éducation et I'information dans le secteur de santé et de planification familiale, amener à l'implentation effective des programmes visant un grand nombre de jeunes femmes namibiennes utilisant des contraceptives.
\end{abstract}




\section{Introduction}

As in many sub-Sahara African countries (Mfono 1998; Prata et al. 2005) young women in Namibia in the age group, 15-24 years, are recurrently exposed to sexual and reproductive health risks and infections, as well as unintended pregnancy and childbirth. The acknowledgement that young women are 'at risk' of unplanned pregnancies, or are 'vulnerable' to infections is now an important health, social and demographic concern in Namibia and has attracted much attention from the government, nongovernmental organizations and the communities at large. Premarital childbearing and unintended pregnancies are on increase in Namibia and this may be attributed to poor education on the topics of sex, contraceptive use or reproductive health in general. Data from the 2000 Demographic and Health survey indicate that 18 percent of teenage women have begun the child bearing process; the median age at first marriage for young women aged 15-24 is 18 years, while the median age at first sexual intercourse is 16 years. Prompted by calls emanating from the 1994 ICPD Programme of Action, the Namibian government introduced a reproductive health and family planning programme with the overall objective of promoting, protecting and improving the health of family members, especially women and adolescents. Whilst there is no detailed or separate policy on adolescent and youth-friendly health services, the reproductive health programme of the Ministry of Health and Social Services is actively targeting the youth to consider their health service needs. In addition, the national school health policy under the Ministry of Education is addressing problems associated with the general health of school-going children and is promoting the development of programmes on life skills and sexual health education (Ministry of Basic education Sport and Culture \& Ministry of Higher Education, Training and Employment Creation, 2003). However, use of contraceptives by young people especially adolescents is a sensitive issue in a country with strong traditional and cultural leanings. Young women face many difficulties when they attempt to obtain contraceptives. Government policy is to "ensure availability and accessibility of contraceptive services for people of reproductive ages who are ready for and need them" but in practice, adolescents have limited access to such services. This result in many reproductive health problems including high rates of unwanted pregnancies, high rates of unsafe abortion; high rate of abandoned babies and high prevalence of sexually transmitted infections including HIV / AIDS.

\section{Sexual reproductive health in Namibia}

Young women's reproductive health needs are often overlooked or viewed through a lens of cultural values that limit care. The socio-cultural context in which young women in Namibia find themselves has changed considerably within the past few generations. As in much of Africa, young women in Namibia are experiencing social turmoil resulting 
from conflicting values as the country becomes more urban and industrial. Periodic abstinence, withdrawal and nonpenetrative sex were taught and widely practised as means of preventing pregnancy in the past. Young women were taught about the "wrong time of the moon", when a girl might get pregnant. However, with urbanisation and promotion of modern practices, most sexual socialization rituals are discarded. Educational functions, which formerly rested within the family and community, are increasingly being taken over by local and national governments, churches and community groups. The need for guidelines and programmatic intervention addressing sexual and reproductive health services problems is clear. However, it requires an understanding of the many factors affecting young women's use of such services including contraceptives, and very little analytical investigation of this subject has been done in Namibia. The main objectives of this paper are therefore:

- To examine factors that influence young women's use and choice of contraceptive methods;

- To examine whether the determinants of contraceptive use differs among married and unmarried young women.

Whilst these objectives are basic ones in demographic and reproductive health studies, they are yet to be provided with a definitive answer in the case of Namibia. We address these objectives through the use of both quantitative and qualitative methods.

\section{Data and Methods}

Source

The Namibian Demographic and Health Survey (NDHS) conducted between September and December 2000 and focus group discussions conducted with young women aged 15-24 in June/July 2004 are the major sources of data used in this study. The NDHS provided secondary data for this study and primary data was generated from the focus groups discussions and are used to complement the quantitative results and provide more in-depth information, which cannot be provided by the DHS. The NDHS is the latest national dataset with information on contraceptive use and yield a representative probability sample of 6500 completed interviews with women between the ages of 15 and 49 and 3000 men aged 15-59 regardless of their marital status. The primary objective of the NDHS was to provide up-to-date demographic information and to produce regional demographic estimates and health indicators. The survey was conducted by the Ministry of Health and Social Services in collaboration with the Central Statistics Office. The Woman's questionnaire was used to collect information from all women aged 1549 years and covered topics such as background characteristics, reproductive history, knowledge and use of contraceptive methods, fertility preferences, maternal mortality, knowledge of HIV/ AIDS etc. Furthermore, a select number of focus group discussions were conducted by the researcher in 2004 to 
build additional and nuanced understandings of young women's attitudes towards health service utilisation, contraceptive use and contraceptive method choice. The data drawn out of focus group sessions are regarded as supplementary to the survey data, to further illuminate the statistical findings. In this study, focus group discussions were deemed vital to fill gaps, which could not be addressed through quantitative data analysis. The following categories of young women were represented in the groups: married and never married, with and without children, current users, non-users of contraceptives, school-goers and school dropouts. In total, six focus groups were held in both urban and rural areas. Each group consisted of 8 to 10 participants. Those in school were interviewed separately from the out-of-school young women and the groups were fairly homogeneous with regard to age. A semistructured group interview format was adopted that ensured that the same subject matter was discussed in each group. However, apart from this guide, the group interviews offered space for the exploration of interesting issues that arose spontaneously. The discussions were audio recorded. Audiotapes were transcribed and focus group discussions that had been conducted in Oshiwambo were translated into English. The audio tapes of each focus group discussion were reviewed several times in order to get an adequate impression of the discussion climate and to construct verbatim transcriptions in which hesitations, silences, enthusiasm, anxiety and other socio-psychological indicators could be 44 noted. The general findings, together with pertinent verbatim quotations, were then organised according to selected themes, so that different attitudes, beliefs and emotions could be illustrated and related to the quantitative data.

\section{Methods of analysis}

Two related processes, viz., the decision to practise contraception and the choice of method determine the prevalence of a specific contraceptive method. Therefore, these processes are modelled here in two stages. In the first stage the determinants of the decision to use contraception are examined. The outcome variable "contraceptive users" in this study refers to sexually experienced young women aged 15-24 and reported that they were using a contraceptive method at the time of the survey. This analysis is therefore based on data gathered from the 1776 young women who were identified as 'sexually experienced' in the NDHS. The determinants of contraceptive use are therefore modelled using a binary logistic regression. It was chosen as the most suitable method because of its ability to detect changes in measurements that are brought about by addition of new variables to the equation. The results of the logistic regression models are converted to odds ratios, which represent the effect of one unit change in the explanatory variable on the indicator of contraceptive use. Odds ratios larger than one (1) indicate a greater likelihood of contraceptive use than for the reference category; odds ratios smaller than one (1) indicate a smaller likelihood compared with the reference category. The 
relevance of a particular independent variable as a predictor of contraceptive use can be determined by comparing the magnitude of the regression coefficient with that of its standard error. Evidence of the usefulness of the independent variable becomes apparent if the coefficient is much larger than its standard error. The best model was determined by looking at the change in the likelihood using the backward stepwise procedure. The 5\% significance level was used as a basis for deciding if a particular variable should be retained in the model. In all cases a reference category was chosen. The models were interpreted in terms of the odds ratios. The odds ratios are generally obtained by taking the exponential of the parameter estimate $\left(\mathrm{e}^{\boldsymbol{0}^{*}}\right)$ and used to compare odds between two groups. The logit model is of the form

$$
\operatorname{logit}(\mathrm{p})=\log \left(\frac{p}{1 \bullet p}\right) \bullet \bullet{ }_{0} \bullet \bullet{ }_{1} x_{1} \bullet \ldots \bullet \bullet{ }_{k} x_{x}
$$

The odds of using contraceptive methods can equivalently be determined in terms of probability of current use, $p$, as

$$
p \bullet \frac{\exp \left(\bullet \bullet_{0} \bullet \bullet{ }_{1} x_{1} \bullet \ldots \bullet \bullet{ }_{k} x_{k}\right)}{1 \bullet \exp \left(\bullet \bullet_{0} \bullet \bullet{ }_{1} x_{1} \bullet \ldots \bullet \bullet{ }_{k} x_{k}\right)}=\frac{1}{1 \bullet e^{z}}
$$

where $z \bullet \bullet{ }_{0} \bullet \bullet{ }_{1} x_{1} \bullet \ldots \bullet \bullet{ }_{k} x_{k}$
In the second stage, determinants of the choice of methods among sexually active young women who are using contraceptives are examined. The outcome variable "method choice" refers to sexually experienced young women 15-24 who reported that they were using a contraceptive method at the time of the survey and therefore considering the method which they were using. The analysis is therefore based on 929 contraceptive users. The interest here is on examining which method is preferred by young women, why it is preferred and what the characteristics of young women are who are using a specific contraceptive method. The response variable is method choice among the commonly used methods in Namibia (the injection, male condom, pill and other methods). All analyses were performed using SPSS. The research variables and how they are measured are shown in Table1. 
African Population Studies Vol. $22 n^{\circ} 2 /$ Etude de la Population Africaine Vol. $23 N^{*} 1$

Table 1: Variables and how they are measured

\begin{tabular}{|c|c|}
\hline Variable & Measure \\
\hline Contraceptive knowledge & ability to mention a birth control methods \\
\hline Contraceptive choice & $\begin{array}{l}\text { specific method us ed classified as whether pill; } \\
\text { injection; condom or other methods at the time of } \\
\text { the survey }\end{array}$ \\
\hline Contraceptive use & $\begin{array}{l}\text { Use of a contraceptive method at the time of the } \\
\text { survey }\end{array}$ \\
\hline Age & age grouped as $15-19$ and $20-24$ \\
\hline Number of living children & $\begin{array}{l}\text { classifies as those who do not have any child and } \\
\text { those who have at least one child }\end{array}$ \\
\hline Region & $\begin{array}{l}\text { classified as Northwest, Northeast, South and } \\
\text { Central as administratively health regions }\end{array}$ \\
\hline Residence & either rural or urban \\
\hline Communication & $\begin{array}{l}\text { Status whether respondent discuss family } \\
\text { planning with partner, mother, friends }\end{array}$ \\
\hline Media & $\begin{array}{l}\text { Status whether respondent listens to radio, } \\
\text { watches TV or read newspapers at least once a } \\
\text { week. }\end{array}$ \\
\hline Education level & education level completed \\
\hline
\end{tabular}

\section{Results}

\section{Respondent characteristics}

The sample for this analysis included 1329 sexually experienced young women who are not married and 447 young women who are married (Table $2)$. The mean age for the married respondents was 21.2 years and for those who were not married was 19.9 years.
Knowledge of contraceptive methods is quite high among young women. However, some methods are commonly known than others. Pill and injectables are the most commonly known methods among both married and unmarried respondents. Male condoms have been available in the Namibian market for sometime, but its popularity is still low. Half or married responds report that they know male condom $(50.3 \%)$ as compared 
to $55 \%$ unmarried women who reported that they also know male condom. The mean age at first sexual intercourse was 16 for unmarried young women and 19 years for married ones. Overall, $75 \%$ of unmarried sexually experienced young women have reported that they had used contraceptive however only $52 \%$ report that they were using contraceptives at the time of survey. This prevalence is still below the Southern African region prevalence level of $60 \%$ (World Population Data Sheet 2006). For the married ones, as high as $81 \%$ had ever used contraceptives and $52 \%$ were using contraceptives at the time of the survey. The most common used method among all respondents was the injection (Table 3). Furthermore, the prevalence of condom use is high among unmarried young women. Only few respondents reported that they use other contraceptive methods i.e. IUD, female condom, withdrawal etc. Most respondents reported that they had obtained contraceptive methods from government hospital or health centers. This is not surprising as most family planning services i.e. provision of condom, injection, pills are free offered at government hospitals in Namibia. Furthermore, the bivariate analysis reveals a significant association between contraceptive use and education level of respondent, respondent's place of residence; whether respondent discuss family planning with partner, mother or friends, respondent's working status and respondent's number of living children (results not presented).

Table 2: Background characteristics of sexually experienced young women Aged 15-24 Namibia 2001

\begin{tabular}{l|c|c}
\hline \multicolumn{1}{c|}{ Characteristics } & Married & Unmarried \\
\hline All & 447 & 1329 \\
Mean age & 21.2 & 19.9 \\
Mean age at first sexual & 19 & 16 \\
intercourse & & $\mathbf{9 8 . 4}$ \\
Contraceptive knowledge (\%) & $\mathbf{9 8 . 6}$ & 95.5 \\
$\quad$ Pill & 95.3 & 96.8 \\
$\quad$ Injection & 93.0 & 55.8 \\
$\quad$ Condom & 50.3 & 29.4 \\
$\quad$ Female condom & 26.9 & 34.2 \\
$\quad$ Rhythm & 32.7 & 6.0 \\
$\quad$ Withdrawal & 8.0 & \\
Contraceptive use & & 75 \\
\% ever use & 81 & 52 \\
\% current use & 52 & \\
\hline
\end{tabular}


Table 3: Percentage distribution of respondents who used a method by methodused and source, according to marital status.

\begin{tabular}{|l|l|l|}
\hline Method and Source & Unmarried $(\mathrm{N}=696)$ & Married $(\mathrm{N}=233)$ \\
\hline
\end{tabular}

\section{Method}

Pill

Injections

49.5

60.9

Condom

38.5

Female condom

0.3

1.7

IUD

0.3

0.4

Periodic Abstinence

0.1

0.4

Withdrawal

0.3

2.1

Others

0.9

0.4

\section{Source}

Government hospital

Friends

Pharmacy

Shops
85.2

89.4

4.6

1.8

0.9

\section{Determinants of contraceptive use}

The logistic regression results (Table 4) show that young women with at least secondary education are more likely to use contraceptives than those who have never been to school (odds ratio $=2.6$ for married women and $\mathrm{OR}=2.8$ for unmarried women). The effect of education on contraceptive use is also explained in the interaction with the status of discussing family planning with partner, for unmarried women. Young women with at least secondary education and discuss family planning with their partner have a high probability of using 
contraceptives than those with no education and do not discuss with their partner. This finding supports evidence from the international literature that displays consistent argument about the regulating and empowering effects of completed secondary education, including increased knowledge of fertility processes and positive attitudes towards use of modern contraception. As is the experience generally, increasing education would also affect the distribution of authority within Namibian households, enabling women to engage partners and parents on issues concerning sexual and intimate relations. The data analysis further reveals that media access also influences young women's use of contraceptive methods. Young women who reported that they listen to radio or read newspapers at least once a week use contraceptives more than those who do not have access to such media. For example, among unmarried young women who state that they listen to the radio at least once a week, $54 \%$ (odds ratio $=1.6$ ) report that they use contraceptives. Similarly, for married women who read newspapers or magazines the odds of using contraceptives equals 1.9. Whilst family planning discussions with partner, mother or friends were not significant as main effect, they had significant interaction effect on contraceptive use. Young adults aged 20-24 who discuss family planning with their partners were more likely to use contraceptives as compared to adolescents who do not discuss family planning with their partners (odds ratio $=1.8$ ). This is in line with the findings of Whitaker et al. (1999) who maintain that communicating with a partner is an important selfprotective health measure that can aid one to learn about a partner's prior sexual behaviour and associated concerns that will inform safer sexual behaviours (see also Benefo 2004). Furthermore, young adults who discuss family planning with their mother were 5.2 times more likely to use contraceptive than adolescents who do not discuss family planning with their mother. For unmarried young women, a significant interaction finding was on discussing family planning with mother and rural-urban residence. Young women in rural areas who discussed family planning with their mothers were more likely to use contraceptives than young women in urban areas who do not discuss family planning with their mothers (odds ratio $=1.9$ ). This is a strong indication of the importance of parental involvement (especially, the mother's intervention) in the reproductive health of young women. In formulating the research concerns of this project, the researchers surmised that young Namibian women who raise the topics of family planning or use of contraceptives with their mothers were likely to be discouraged or reprimanded for their pre-marital sexual activity, particularly in this era of increasing levels of HIV infection. Alternatively, if talking about family planning led to increased use of contraceptives, this could suggest receptiveness, or a liberal pragmatism, on the part of mothers that could be harnessed in the interests of young women's health and that could consequently boost state initiatives to increase access to family planning. Peer influence had a significant effect on contraceptive use for unmarried 
young women. The results shows that young adults (unmarried) who discuss family planning with their friends were more likely to use contraceptive than adolescent women who do not discuss family planning with their friends (odds ratio $=1.5$ ). This finding is supported with evidence from focus group discussions where some young women indicated that they discussed contraceptive use mainly with their friends, who were an important source of influence and information, especially for unmarried young women. Access to health facility in terms of distance is also a significant determinant of contraceptive use among unmarried young women. Young women who live in rural areas and requires at least one hour to get to health facility have a low likelihood of using contraceptives (odds ratio $=0.7$ ) than those in urban areas and takes less than an hour to get to health facility.

Table 4 Odds ratios of the likelihood of using contraceptive methods among married and unmarried young women aged 15 - 24, Namibia 2001.

\section{Characteristic}

Married

Unmarried

\section{Age}

$15-19$ (ref)

1.00

ns

$20-24$

0.61

ns

\section{Number of living children}

None(ref)

At least one

\section{Education level}

Never been to schoo(ref)

Primary

Secondax or higher

Read newspaper at least once a week

No (ref)

1.00

2.56

2.70

ns

1.00

S 
Not employed(ref)

Employed

Region

Northwest(ref)

Northeast

Central

South

\section{Listen to radio at least once a week}

No (ref)

Yes

\section{Interactions}

Aged 20 - 24 \& Discuss FP with partner

Aged 20 - 24 \& Discuss FP with mother

Aged 20 - 24 \& Discuss FP with friends

Primary education \& Discuss FP with partner

Secondary education \& Discuss FP with partner

Live in rural \& Discuss FP with mother

Takes more than an hour to health facility \& live in rural ns

1.00

ns

$1.31^{*}$

ns

1.00

ns

$1.89 * *$

ns

$2.22 * *$

ns

1.18

ns

1.00

ns

$1.58 * *$

1.83

ns

5.18

ns

0.44

$1.49 * *$

ns

1.15

ns

$1.86^{*}$

ns

$1.86^{*}$

ns

$0.75 *$

${ }^{*}$ significant at $\mathrm{p}<0.05 ; * * \mathrm{p}<0.001 ; \mathrm{ns}=$ not significant; ref $=$ reference category. 
Determinants ofmethod choice

Young women decide on what contraception to use on the basis of what is available and most convenient at the time (Agyei \& Miggade 1995). The results of the present study show a greater prevalence of modern contraceptive methods: the injection had the highest prevalence, followed by the male condom and then the pill. Table 5 presents the determinants of method choice. The odds of using injection for young women with at least one child is 3.4 times higher than the odds of young women using injection and have no child (ren). This is an indication that most young women who have at least one child chose long acting methods than those who have no children. Fear of infertility at later stage could be one of the reasons why young women with no children do not use long acting methods. This is exemplied in this statement: "I don' thave any problem with the condom but regarding other methods of contraception, there can be side effects. For example, someone who uses pills to avoid unwanted pregnancy can find themselves left sterile forever". (out of school, 19, FG 4, 2004). On the other hand, for those who are married, they perhaps want to start childbearing as childless marriage in most societies are not respected. Media access and status of discussing family planning with friends are important determinants of condom use. From the focus group discussion a similar finding was highlighted by one of the participants: "I decided to use contraceptives because every time I discuss with my friends about contraceptives, everyone talks about them in a positive manner, no one criticizes them. Maybe they also use contraceptives" (in school, aged 19, FG3, 2004).

Exposure to family planning messages through radio are strongly associated with contraceptive use and safe sex media campaigns are associated with increased teen condom use with (Namibia Broadcasting Corporation, 2001) casual partners and reduction in the number of teenagers reporting sexual activity. The Namibian Broadcasting Corporation has several educative and informative dramas relating to sexual and reproductive health in all Namibian languages, which are of importance to young people. Those who listen to such programmes through the radio can learn from them. From the focus group discussions some young women reported being fearful and being too shy to be seen at health facilities for sexual and reproductive health services by older people and by their friends. Thus, if information is aired in media to which they can listen, it will be to their advantage. Access to health facility in terms of distance to obtain family planning services is also a significant determinant in method choice. Young women who take more than an hour to get to the health facility are more likely to use the pill than those who are less than an hour away from health facility (odds ratio = 1.96). On the other hand, young women from focus groups were not in favour of some health facilities which are too close to their homes because they ran into family members and neighbours every time they sought services. This is supported by a young woman who explained that "The society we live in is not supporting young unmarried women to get sexual and 
reproductive health services. Therefore, if you from where you live, so that you are not seen by are really strong enough, you can walk long people who know you" (rural, aged 23, FG 4, distances to go to the clinic which is a bit far 2004).

Table 5: Odds ratios from logistic regression analyses examining the use of specific methods among young women.

\begin{tabular}{l|l|l|ll}
\hline & Pill & Condom & Injectables & Other methods \\
\hline
\end{tabular}

Number of living child (ren)

None (ref)

At least one

Time to health facility

Less than an hour (ref)

More that an hour

Discuss FP with mother

No (ref)

Yes

\section{Discuss FP with friends}

No (ref)

Yes

\section{Listen to radio at least once a week}

No (ref)

Yes

Watch TV at least once a week
1.00

$1.96 * *$
1.00

0.13

$2.05 * *$

na

1.00

na

$0.61 *$

na

na

na

na

na

na na

na
$3.4 * * *$ 


\section{Conclusion}

The study maintains that urgent policy issues should be addressed if the Namibian vision 2030 contraceptive prevalence rate is to be achieved. The key policy recommendation here is that the government of Namibia should initiate a comprehensive Parent Education Programme on young peoples' sexual and reproductive health, the main purpose being to break down the poor communication between parents and children on sexual issues. Considerable work remains to be done in Namibia to fully implement national policies on young peoples' health services. Priorities include ensuring the capacity to provide key services, strengthening the quality of care standards and orienting clinic staff to young peoples' sexual and reproductive health care, particularly in the area of counselling and appropriate ethical behaviour. This will require special training for clinic staff on young people's sexual and reproductive health needs, with special emphasis on the need for confidentiality. From the focus groups it was apparent that some of the more significant barriers to health service utilisation among Namibian young women appear to be psycho-social in nature. Increasing health service use will require changes in the attitudes and perceptions of young people at community level as well as some changes in values held by Namibian parents and adults in general. Overall, factors influencing young women to use contraceptives differ among married and unmarried ones. However, contraceptive use increases with level of education among both married and unmarried young women. Thus, the need to enhance sexual and reproductive health education programmes in and out of school is urgent to counter the high level of misunderstandings noted with regard to contraceptive use. This necessitates educational efforts outside the traditional classroom and clinic realm and within the structures of broader society. One of the huge gaps identified in the Namibian case is that young women have nowhere to turn to for information and guidance. This restricts both their use and choice of methods. Despite the fact that there are basic services and initiatives in place, this need was repeatedly expressed by young women in this study. Some of them fear talking to their parents, health care providers and to other adult members and, in most cases, their peer group discussions leave many questions unanswered. The fact that most information about reproductive health issues come from TV, radios and peers further highlights the lack of authoritative personal guidance in this matter. What is needed to fill the knowledge-use gap are interventions that offer appropriate messages with an emphasis on 'risk reduction' and elucidation of 'choice'. 


\section{References}

Agyei W.K. and Migadde M. 1995. "Demographic and socio-cultural factors influencing contraceptive use in Uganda." Journal of Biological Sciences 27,(1): 47-60.

Benefo K.D. 2004. “Are partner and relationship characteristics associated with condom use in $\mathrm{Z}$ a m bi a n no n m a r i a 1 relationships?" International family planning perspectives 30, (3): 118127.

Mfono Z. 1998. “Teenage contraceptive needs in urban South Africa: A case study." International family planning perspectives 24, (4):180-183.

Ministry of Basic Education, Sport and Culture (MBESC) and the Ministry of Higher Education, Training and Employment Creation (MHETEC). 2003. National Policy on HIV and AIDS for the education sector.
Windhoek, Republic of Namibia.

Namibian Broadcasting Corporation. 2001. Take Control HIV/AIDS media campaign, HIV and young people. Issue 2, January: Windhoek.

Prata N., Vahidnia F. and Fraser A. 2005. "Gender and relationship differences in condom use among 15-24 year olds in Angola." International family planning perspectives 31, (4): 192-199.

Whitaker D.J., Miller K.S., May D.C. and Levin M.L. 1999. “Teenage partners' communication about sexual risk and condom use: The importance of parent-teenage discussions." Family planning perspectives 31,(3):117-121.

World Population Data Sheet. 2006. Population Reference Bureau. New York: United Nations. 